\title{
Acupuncture and Its Role in the Treatment of Migraine Headaches
}

\author{
Ivan Urits · Megha Patel · Mary Elizabeth Putz · Nikolas R. Monteferrante • \\ Diep Nguyen · Daniel An · Elyse M. Cornett · Jamal Hasoon · \\ Alan D. Kaye · Omar Viswanath
}

Received: August 13, 2020 / Accepted: September 23, 2020 / Published online: October 1, 2020

(C) The Author(s) 2020

\section{ABSTRACT}

Acupuncture is a form of traditional Chinese medicine that is performed by placing needles or pressure in specific locations on a patient's

Digital Features To view digital features for this article go to https://doi.org/10.6084/m9.figshare.12981695.

I. Urits $(\bowtie) \cdot$ J. Hasoon

Department of Anesthesia, Critical Care, and Pain Medicine, Beth Israel Deaconess Medical CenterHarvard Medical School, Boston, MA, USA

e-mail: ivanurits@gmail.com

M. Patel · M. E. Putz · D. Nguyen · O. Viswanath Department of Anesthesiology, University of Arizona College of Medicine-Phoenix, Phoenix, AZ, USA

N. R. Monteferrante · O. Viswanath Department of Anesthesiology, Creighton University School of Medicine, Omaha, NE, USA

D. An

Georgetown University School of Medicine, Washington, DC, USA

E. M. Cornett · A. D. Kaye · O. Viswanath Department of Anesthesiology, Louisiana State

University Health Shreveport, Shreveport, LA, USA

O. Viswanath

Valley Pain Consultants-Envision Physician

Services, Phoenix, AZ, USA skin to achieve a therapeutic effect. Although used to treat a variety of disorders, one of the most common applications of acupuncture is to treat chronic pain, especially headache and migraine pain. Migraines are difficult to treat, and pharmacotherapies are often the first line of treatment, although these options have many unwanted side effects, such as exacerbation of headache pain in those with chronic migraine. Many complimentary and integrative therapies are available to treat migraine (including nutraceuticals, yoga, tai chi, and biofeedback), among which acupuncture as a treatment is gaining increasing attention. In this review, we provide an overview of the current understanding of both acupuncture and migraine and of current research investigating the effectiveness of acupuncture in treating migraine and chronic migraine.

Keywords: Acupuncture; Chronic pain; Migraine 


\section{Key Summary Points}

Acupuncture is gaining increasing attention as a viable addition to the physician's armamentarium for the management of migraine patients.

Evidence is available showing acupuncture's measurable effects on both the duration and frequency of migraine attacks.

In many studies, acupuncture has been shown to be a safe, efficacious and readily available alternative therapy which may be beneficial to certain migraine patients.

Further investigation is required to ensure that the incorporation of acupuncture into migraine treatment management will have a positive outcome on patients.

\section{DIGITAL FEATURES}

This article is published with digital features to facilitate understanding of the article. To view digital features for this article go to https://doi. org/10.6084/m9.figshare.12981695.

\section{INTRODUCTION}

Acupuncture is a form of traditional Chinese medicine which utilizes needles placed in specific acupoints on the skin to generate healing and restore balance within the human body. Although used to treat a variety of disorders, one of the most common uses is the treatment of chronic pain, especially headache and migraine pain [1]. Migraine is a complex neurologic disorder characterized by significant disability in day-to-day life due to pain and symptoms associated with attacks. Migraines are difficult to treat, and current treatment options have many unwanted side effects and can even exacerbate headache pain in those with chronic migraines [2]. In addition, many patients who experience migraines encounter difficulties in getting correctly diagnosed and subsequently in accessing the care that they need [3]. This has led many clinicians and researchers to turn to other forms of treatment, such as acupuncture, as an alternative source of pain management and healing for those who suffer from migraine refractory to standard pharmacological treatment. In this review, we analyze the current understanding of both acupuncture and migraine and assess current research on the effectiveness of acupuncture in treating migraine and chronic migraine.

This article is based on previously conducted studies and does not contain any studies with human participants or animals performed by any of the authors.

\section{ACUPUNCTURE}

Acupuncture is a healing modality in TCM with strong ties to Confucianism and Taoism that can be definitively traced back to $100 \mathrm{BC}$ [4]. Techniques continued to evolve throughout the centuries as support varied under different governments, but ultimately it experienced a resurgence under Communist rule in China in 1949 , resulting in the creation of TCM as a compilation of various forms of acupuncture [4]. The spread of acupuncture to Western nations occurred in varying timelines, with exposure starting to increase in the USA during the Nixon administration [5]. Acceptance in the US medical community increased in 1998 when the National Institutes of Health published a consensus on the efficacy of acupuncture as an analgesic for postoperative dental pain and treatment for postoperative and chemotherapyinduced nausea and vomiting [6]. Since then, acupuncture has continued to grow in popularity across the country as many academic hospitals now incorporate acupuncture into a comprehensive treatment plan, and insurance companies are more likely to cover the cost of treatment [7]. An estimated $1.5 \%$ of the US population has received acupuncture treatment at least once, often in addition to the established standard of care regimens [7]. 
Acupuncture is performed by placing needles or pressure in specific locations on a patient's skin to achieve a therapeutic effect. There is an emphasis on the human experience of pain and sensation, which is rooted in an understanding of the concepts of qi and yin and yang. Qi refers to the belief in a "vital energy" that exists in each person and represents a state of innerconnectedness which is obtained through the relationship with the natural world via elements of wood, fire, earth, water, and metal $[5,7]$. Yin and yang refer to the concept of balance in forces in the physical world, with yin representing receptivity, tranquility, rain, cold, and femininity, and yang representing strength, excess, daylight, heat, and masculinity $[5,8]$. Acupuncture aims to realign the flow of qi through the body and balance a person's internal yin and yang to re-establish harmony [8]. This synchronization is achieved by utilizing a complex map of the human body with up to 365 specific points on the skin which correspond to underlying meridians (or channels) that exist as a matrix within the human body [8]. Depending on the diagnosis and type of treatment indicated, acupuncturists will choose which points will be included in the treatment and how many sessions are required. When studied under the lens of Western physiology, studies suggest that analgesia comes from the stimulation of muscles targeting high-threshold and small-diameter nerves, ultimately reaching key brain structures which result in endogenous opioid release [8]. Other studies propose a mechanism of micro-injury from the needles, which promotes the body's healing and blood flow response [9]. Functional magnetic resonance imaging (fMRI) studies provide data supporting a direct link between acupuncture points and specific brain activity. In one study, targeting of an acupoint traditionally associated with vision resulted in the activation of the same region of the occipital lobe known to be activated by shining a light into the eye [10]. Acupuncture is largely well-tolerated and safe for patients if the provider is properly trained [8]. Numerous research studies have analyzed the effects of acupuncture on migraine and various disease states, including urinary tract infections, depression, poststroke spastic hemiplegia, musculoskeletal pain, and peripheral neuropathy [1, 11-15].

\section{MIGRAINE}

\section{Epidemiology}

Migraine and its sub-categories are diagnoses associated with significant disability, including frequent occurrences of missed school or work, inability to perform household chores, and missed time with family and friends [2]. The prevalence of migraine worldwide is $14.7 \%$, and the prevalence of chronic migraine (CM) worldwide ranges from 0 to $5.1 \%$, with estimates usually in the range of $1.4-2.2 \%$ [16]. In the USA, the prevalence of migraine overall is $15.3 \%$ (9.7\% of males and $20.7 \%$ of females), with $\mathrm{CM}$ prevalence ranging from 1.3 to $4.1 \%$ and representing about $8 \%$ of cases in those with migraine $[2,16-18]$. Around $36 \%$ of migraines have an associated aura [19]. According to the World Health Organization, migraine is the eighth most disabling disease worldwide, the most burdensome neurologic disease, and responsible for $5.6 \%$ of years lost to disability $[20,21]$. General trends show that migraine prevalence is affected by age, sex, and socioeconomic status (SES), with higher rates in females throughout their lives, and a peak in prevalence in both men and women in their 40s [17]. The overall highest prevalence is in females aged 18-49 years, and there is a higher prevalence of migraine and CM in those with a lower SES [17]. Episodic migraine often precedes $\mathrm{CM}$ with an annual conversion rate of about $3 \%$ [2]. Specific risk factors for migraine include overuse of acute migraine medications, obesity, depression, female sex, and high levels of stress [2]. In contrast, some important protective factors include properly dosed preventive medication, higher education level, being married or having strong social ties, exercise, and robust personal stress management [2]. 


\section{Pathophysiology}

Migraine is a disorder of the body's pain modulatory system in which underlying neural networks are disrupted, particularly in the trigeminovascular system [22]. Four main phases have been described to characterize the progression of a migraine: premonitory phase, aura phase, headache phase, and postdrome phase [23]. Migraines do not always follow this linear pattern, and not all migraines have these distinct phases. In the premonitory phase, positron emission tomography and fMRI studies show evidence of hypothalamic, thalamic, and cortical activation during this phase which correlates with symptoms such as yawning, polyuria, irritability, photophobia, mood changes, difficulty concentrating, and neck pain $[23,24]$. Important hypothalamic neurotransmitters, including dopamine, have been identified to play a role in the modulation of migraine and thus serve as a potential therapeutic target [23]. The aura phase involves disruptive changes in the sensorium in which visual auras, such as scotomas, are the most common type, but these can also present as olfactory, sensory, or language changes [24]. The pathophysiology of migraine in the aura phase is described by the concept of cortical spreading depolarization, in which vasoactive substances, such as nitric oxide, are released, resulting in increased cerebral blood flow [23]. The headache phase is driven by pain perception communicated from peripheral afferents to central control centers for pain, including cortical, vascular, and autonomic locations which make up the trigeminocervical complex [23]. The postdrome phase is the resolution of the migraine driven by vasoconstriction and reduced cerebral blood flow that often presents with symptoms such as fatigue, difficulty concentrating, nausea, and irritability [23]. Additionally, it is known that calcitonin generelated peptide (CGRP) is released into the circulation during migraines and cluster headaches, and that its levels drop after administration of a triptan [24]. There is increasing evidence demonstrating the presence of persistently elevated levels of CGRP in patients with CM [24].

\section{Diagnosis}

Migraine without aura is defined by at least five attacks that last between 4 and $72 \mathrm{~h}$, have at least two defining characteristics (unilateral, pulsating, moderate, or severe pain, aggravated by or leading to purposely avoiding physical activity), have at least one associated symptom (nausea, vomiting, photophobia, or phonophobia), and cannot be explained by another medical cause [25]. Migraine with aura describes a migraine in which the person experiences some type of sensation associated with the onset of a migraine. Diagnostic criteria dictate that the aura symptoms can be sensory, visual, motor, speech/language, retinal, or brainstem related, and that the migraine must have three of the following characteristics: one aura symptom that gradually spreads over $\geq 5 \mathrm{~min}$; each individual aura lasts 5-60 min; at least one aura symptom is unilateral; and the aura is accompanied by or followed by headache within $60 \mathrm{~min}$ [26]. Episodic migraine is diagnosed in those who have headaches that occur on 0-14 days per month and meet the criteria for a migraine headache [27]. CM is defined as $\geq$ 15 days of headache per month for more than 3 months, in the absence of other causes, with the headache meeting requirements of migraine with or without aura for at least 8 days per month, and in a patient with a lifetime history of at least five migraines [27, 28]. Examples of other medical causes of migraines include giant cell arteritis, trigeminal post-herpetic neuropathy, sleep apnea, and polypharmacy, all of which are common in the elderly population and need to be ruled out before a diagnosis of migraine or CM can be made [29].

\section{TRADITIONAL TREATMENTS FOR MIGRAINE}

The current treatment of acute migraine is primarily drug therapy [24]. Medications are more likely to be effective if given early in the development of symptoms and administered with the proper dosage and route of administration [25]. Studies have suggested that under-treating acute attacks can lead to the development of 
chronicity through a sensitization process [2]. Several pharmacological and non-pharmacological methods have traditionally been used as both prophylactic and acute treatments of migraines. For the treatment of mild to moderate pain, over-the-counter nonsteroidal antiinflammatory drugs (NSAIDs) can be effective, but for the treatment of moderate to severe pain, triptans are the first-line medication [25]. The serotonin $5-\mathrm{HT}_{1 \mathrm{~B}}$ and $5-\mathrm{HT}_{1 \mathrm{D}}$ receptor agonists, collectively known as triptans, are central to migraine treatment and play a key role in the modulation of migraine pain due to their action on the $5-\mathrm{HT}_{1 \mathrm{~B}}$ and $5-\mathrm{HT}_{1 \mathrm{D}}$ receptors, which are located on peripheral trigeminal nerve endings [25]. Triptans $\left(5-\mathrm{HT}_{1 \mathrm{~B}} / \mathrm{1D}_{\mathrm{D}}\right)$ have long been used as an abortive method to treat acute pain [30]. Ergot alkaloids, whose mechanism of action involves a complex interaction between a number of receptors, including 5-HT, dopamine, and noradrenaline receptors, have also been used as an abortive strategy for migraine attacks [31]. Other medications traditionally used in the treatment of acute migraines include NSAIDs, dopamine antagonists, such as metoclopramide, which is also used in the treatment of nausea and vomiting, corticosteroids, opioids, and acetaminophen alone or in combination with other medications, such as acetaminophen with caffeine, opioids, or barbiturate compounds [32]. Nonpharmacological methods include a single-pulse transcranial magnetic stimulation device that has been described as another possible abortive method for migraine attacks [33].

Preventive medication is usually saved for patients who have frequent attacks or a diagnosis of CM, as long-term use of analgesics can lead to the development of medication-overuse headache [2]. Some common medications used for long-term prevention are beta-blockers, antidepressants, calcium-channel blockers, anticonvulsants, and angiotensin-converting enzyme inhibitors [25, 34]. OnabotulinumotoxinA, otherwise known as BOTOX, has also been an effective strategy that physicians have utilized for prophylactically treating $\mathrm{CM}$ headaches [35]. For non-pharmacological methods, trigeminal neurostimulation with a supraorbital transcutaneous stimulator has been one approach used to prevent migraine attacks [36]. Other non-pharmacological methods that have shown efficacy in preventing migraine attacks include riboflavin and coenzyme Q10, both of which are enzymes that play a crucial role in generating energy within the mitochondria, possibly suggesting that mitochondrial dysfunction might play some role in the pathophysiology of migraine headaches [37].

\section{EVIDENCE FOR ACUPUNCTURE}

Acupuncture is a relatively recent treatment option for migraines. The Cochrane Systematic Review (2016), a commonly cited source, has reported acupuncture to be a useful alternative treatment that reduces the duration and frequency of migraine-both chronic and episodic [38]. Multiple studies have shown some levels of superiority of acupuncture over sham acupuncture [39, 40], and there is moderate evidence for acupuncture being at least noninferior to conventional drug therapy (e.g., topiramate, for episodic migraine prevention), with one study proposing the superiority of acupuncture over propranolol based on an indirect comparison analysis [38, 41]. Currently, acupuncture is considered to be a safe, helpful, and available alternative option for patients who have not responded to or complied with conventional pharmacotherapy; it is also worth mentioning that there are far more acupuncture studies in the adult population than in the pediatric population [42]. Acupuncture therapy is only effective after a certain number of sessions (minimum 6-8), but the most effective timing (e.g., frequency of visits, when to initiate acupuncture) has not yet been determined [43].

In this section we present and discuss various studies conducted on acupuncture. Table 1 presents a summary of these studies. This review includes several of the most recent randomized control trials (RCTs) and meta-analyses to help formulate conclusions on the safety and efficacy of using acupuncture to treat migraine headaches. 
Table 1 Evidence for the use of acupuncture to to migraine

\begin{tabular}{|c|c|c|c|}
\hline $\begin{array}{l}\text { First } \\
\text { author of } \\
\text { study } \\
\text { (year) }\end{array}$ & Groups studied and intervention & Results and findings & Conclusions \\
\hline $\begin{array}{l}\text { Coeytaux } \\
\text { et al. } \\
(2016) \\
{[38]}\end{array}$ & $\begin{array}{l}\text { For patients with migraine } \\
\text { headaches, } 22 \text { studies were } \\
\text { analyzed } \\
\text { For patients with tension-type } \\
\text { headaches, } 12 \text { studies were } \\
\text { analyzed } \\
\text { For patients with chronic } \\
\text { headaches, } 29 \text { studies were } \\
\text { analyzed }\end{array}$ & $\begin{array}{l}\text { With regard to migraine } \\
\text { headaches, the authors } \\
\text { summarized the } 2016 \text { Cochrane } \\
\text { Systematic Review ( } n=22 \\
\text { studies, } 4985 \text { patients), which } \\
\text { highlights acupuncture's } \\
\text { statistically significant } \\
\text { symptomatic improvement at } \\
2 \text { months (compared with both } \\
\text { drug treatment and usual care), } \\
\text { and at the } 3-4 \text { and 5-6 month } \\
\text { time-points (compared with } \\
\text { usual care only) }\end{array}$ & $\begin{array}{l}\text { Based on comparative studies from } \\
\text { systematic reviews, there is } \\
\text { evidence of the effectiveness of } \\
\text { acupuncture as an adjunctive } \\
\text { treatment for primary headache } \\
\text { disorders. More studies are } \\
\text { needed on the adverse effects } \\
\text { and potential placebo effects }\end{array}$ \\
\hline $\begin{array}{c}\text { Li et al. } \\
(2020) \\
{[59]}\end{array}$ & $\begin{array}{l}15 \text { Systematic reviews studying } \\
\text { effectiveness of acupuncture for } \\
\text { patients with migraine } \\
\text { headaches }\end{array}$ & $\begin{array}{l}\text { Based on the A MeaSurement } \\
\text { Tool to Assess Systematic } \\
\text { Reviews } 2 \text { (AMSTAR2) tool, } 1 \\
\text { study was of low quality, while } \\
14 \text { studies were of critically low } \\
\text { quality. Based on the Risk Of } \\
\text { Bias in Systematic Reviews } \\
\text { (ROBIS) tool, } 9 \text { studies had } \\
\text { overall low risk of bias. } \\
\text { Compared to sham medicine } \\
\text { and Western medicine, } \\
\text { acupuncture was observed to be } \\
\text { more effective because it reduced } \\
\text { usage of painkillers and reduced } \\
\text { headache frequency/ } \\
\text { degree/duration }\end{array}$ & $\begin{array}{l}\text { Based on various systematic } \\
\text { reviews comparing acupuncture } \\
\text { to sham acupuncture and } \\
\text { Western medicine, acupuncture } \\
\text { has been supported as an } \\
\text { effective method of treating } \\
\text { migraine headaches. However, } \\
\text { the authors advocate for more } \\
\text { improvement of study } \\
\text { methodology }\end{array}$ \\
\hline $\begin{array}{c}\text { Xu et al. } \\
(2020) \\
{[49]}\end{array}$ & $\begin{array}{l}\text { Multicentered ( } 7 \text { hospitals) } \\
\text { randomized clinical trial with } \\
150 \text { acupuncture-naive patients } \\
\text { presenting with episodic } \\
\text { migraines without aura. } \\
\text { Intervention: } 20 \text { acupuncture } \\
\text { sessions vs. non-penetrative } \\
\text { sham acupuncture }\end{array}$ & $\begin{array}{l}\text { When compared to sham } \\
\text { acupuncture, the 20-session } \\
\text { acupuncture treatment yielded } \\
\text { statistically significant } \\
\text { differences in reducing migraine } \\
\text { frequency (week 17-20) and } \\
\text { duration (week 13-20) }\end{array}$ & $\begin{array}{l}\text { This multicentered, randomized } \\
\text { controlled clinical trial provides } \\
\text { support for acupuncture } \\
\text { treatment as an effective } \\
\text { alternative treatment for } \\
\text { patients with episodic migraines } \\
\text { without aura. A limitation of } \\
\text { the study is the lack of } \\
\text { information on baseline drug } \\
\text { prophylaxis on each patient }\end{array}$ \\
\hline
\end{tabular}


Table 1 continued

\begin{tabular}{|c|c|c|c|}
\hline $\begin{array}{l}\text { First } \\
\text { author of } \\
\text { study } \\
\text { (year) }\end{array}$ & Groups studied and intervention & Results and findings & Conclusions \\
\hline $\begin{array}{l}\text { Zhang et al. } \\
\qquad(2020) \\
{[58]}\end{array}$ & $\begin{array}{l}7 \text { RCTs on patients with } \\
\text { migraines ( } \pm \text { aura) comparing } \\
\text { acupuncture to standard } \\
\text { migraine prophylaxis }\end{array}$ & $\begin{array}{l}\text { Several studies (4/7) showed } \\
\text { statistically significant } \\
\text { superiority of acupuncture over } \\
\text { drug therapy }\end{array}$ & $\begin{array}{l}\text { The authors comment how the } \\
\text { heterogeneity and } \\
\text { variability (e.g., acupuncture } \\
\text { protocol, lack of management } \\
\text { standardization) across the } \\
\text { studies made it difficult to } \\
\text { definitely endorse acupuncture; } \\
\text { however, there is growing } \\
\text { evidence showing the } \\
\text { effectiveness and safety of } \\
\text { acupuncture for migraine } \\
\text { prophylaxis }\end{array}$ \\
\hline $\begin{array}{l}\text { Li et al. } \\
\qquad(2019) \\
{[56]}\end{array}$ & $\begin{array}{l}13 \text { RCTs ( } n=1559 \text { patients) } \\
\text { comparing electroacupuncture } \\
\text { (EA) to various control methods } \\
\text { (e.g., Western medicine, Sham- } \\
\text { EA, blank control) }\end{array}$ & $\begin{array}{l}\text { EA was observed to have a } \\
\text { statistically significant } \\
\text { improvement when compared } \\
\text { with acupoint gut embedding, } \\
\text { sham-EA, and acupuncture with } \\
\text { sham-EA based on the VAS } \\
\text { score }(p<0.05)\end{array}$ & $\begin{array}{l}\text { EA is an effective treatment for } \\
\text { reducing migraine duration } \\
\text { when compared with other } \\
\text { forms of therapy; however, the } \\
\text { lack of differences in adverse } \\
\text { effects warrants further study }\end{array}$ \\
\hline $\begin{array}{l}\text { Zhang et al. } \\
\qquad(2019) \\
{[39]}\end{array}$ & 15 Systematic reviews & $\begin{array}{l}\text { Studies showed acupuncture to be } \\
\text { more effective than drug } \\
\text { therapy, sham acupuncture, and } \\
\text { traditional Chinese } \mathrm{m}\end{array}$ & $\begin{array}{l}\text { Acupuncture has been reported to } \\
\text { be useful in reducing migraine } \\
\text { frequency, duration, and VAS } \\
\text { score, which positions it to be a } \\
\text { helpful treatment for prevention } \\
\text { and management; however, the } \\
\text { subjectivity of outcomes } \\
\text { measures and low sample sizes } \\
\text { highlight the need for more } \\
\text { high-quality studies }\end{array}$ \\
\hline $\begin{array}{l}\text { Chen et al. } \\
\qquad(2020) \\
{[41]}\end{array}$ & $19 \operatorname{RCTs}(n=3656)$ & $\begin{array}{l}\text { Indirect comparison analyses show } \\
\text { that acupuncture has advantages } \\
\text { over propranolol in reducing } \\
\text { migraine frequency, number of } \\
\text { episodes, and adverse effects }\end{array}$ & $\begin{array}{l}\text { Acupuncture may be considered to } \\
\text { be a first-line agent for migraine } \\
\text { prophylaxis someday given the } \\
\text { preliminary data here showing } \\
\text { its effectiveness and safety when } \\
\text { compared to propranolol }\end{array}$ \\
\hline
\end{tabular}


Table 1 continued

\begin{tabular}{|c|c|c|c|}
\hline $\begin{array}{l}\text { First } \\
\text { author of } \\
\text { study } \\
\text { (year) }\end{array}$ & Groups studied and intervention & Results and findings & Conclusions \\
\hline
\end{tabular}

Allais et al. Single-cohort study of EAP one session every 3 weeks for patients with chronic migraines ( $n=20$ women $)$

Liao et al. Retrospective study on patients

[44]

Farahmand

et al.

[48]

$$
\text { with migraines }(n=21,209)
$$

with $1: 1$ propensity score matching to control for various demographic information (e.g., sex, age, income). The comparison was between 1948 acupuncture users and 1948 non-acupuncture users

Participants $(n=45)$ spread across 3 groups:

(1) Migraine without aura

(2) Cervicogenic headache

(3) Healthy controls

The two patient groups received verum accupuncture, while the healthy controls received a sham treatment

Patients with diagnosis of acute migraine attacks $(n=60)$

Some patients received acupuncture, while some patients received a placebo
The mean reduction in the frequency of migraine episodes/month was $6.31 \pm 4.64$ days after 1 month; no significant reductions were observed in the second month. There were minimal adverse effects

There was a statistically significant reduction in cumulative incidence of anxiety, depression, and medical expenditure in the acupuncture users cohort versus the non-acupuncture users cohort

There was a significant increase in $N$-acetylaspartate/creatine in the bilateral thalamus after acupuncture treatment in patients with migraines without aura, which was associated with a decrease in headache intensity score

The acupuncture group had significantly lower pain scores at intervals up to $1 \mathrm{~h}$ posttreatment; however, there was no significant difference between the two groups at 2, 3, or 4 post-treatment
The data provide support for using EAP as prophylaxis for chronic migraine patients. The authors note the small sample size and discuss how more frequent sessions may increase the treatment's efficacy

The data provide support for using acupuncture in migraine patients with common comorbidities of depression and anxiety

Acupuncture significantly increases certain brain metabolites involved in the transmission of pain during migraines, which could explain how acupuncture is able to effectively relieve migraine-associated pain

There is no significant difference in pain scores between the acupuncture group and the placebo group following intervention 
Table 1 continued

\begin{tabular}{|c|c|c|c|}
\hline $\begin{array}{l}\text { First } \\
\text { author of } \\
\text { study } \\
\text { (year) }\end{array}$ & Groups studied and intervention & Results and findings & Conclusions \\
\hline $\begin{array}{l}\text { Musil et al. } \\
\qquad(2018) \\
{[50]}\end{array}$ & $\begin{array}{l}\text { Patients with a diagnosis of } \\
\text { migraines } \\
\text { Patients either received } \\
\text { acupuncture }(n=42) \text { or a } \\
\text { standard pharmacological } \\
\text { treatment }(n=44)\end{array}$ & $\begin{array}{l}\text { Number of migraine days was } \\
\text { reduced more in the } \\
\text { acupuncture than the } \\
\text { medication group ( } 5.5 \text { vs. } 2.0 \\
\text { days) after } 12 \text { weeks of } \\
\text { intervention. Number of } \\
\text { migraine days per } 4 \text { weeks was } \\
\text { reduced more at the end of a } \\
\text { 6-month follow-up in the } \\
\text { acupuncture group (difference: } \\
-4 \text {; } 95 \% \text { CI }-6 \text { to }-2 \text { ). } \\
\text { Number of responders to the } \\
\text { intervention was higher in the } \\
\text { acupuncture group ( } 50 \text { vs. } 27 \% \text {; } \\
p<0.05 \text { ) at the end of the } \\
\text { treatment period, and at the } \\
6 \text {-month follow-up ( } 81 \text { vs. } 36 \% \text {; } \\
p<0.001 \text { ) }\end{array}$ & $\begin{array}{l}\text { Acupuncture therapy can reduce } \\
\text { symptoms and medication use in } \\
\text { both the short- and long term, } \\
\text { and serves as an effective } \\
\text { alternative to pharmacological } \\
\text { treatments for migraines }\end{array}$ \\
\hline $\begin{array}{l}\text { Naderinabi } \\
\text { et al. } \\
(2016) \\
{[51]}\end{array}$ & $\begin{array}{l}\text { Patients with the diagnosis of } \\
\text { chronic migraine }(n=150) \\
\text { Patients received botulinum toxin- } \\
\text { A, acupuncture, or sodium } \\
\text { valproate } 500 \mathrm{mg} / \text { day (control } \\
\text { group) }\end{array}$ & $\begin{array}{l}\text { Patients who received acupuncture } \\
\text { had the greatest reduction in } \\
\text { pain severity at the end of the } \\
\text { 3-month study }(p=0.0001) \text {. In } \\
\text { all groups, the number of days } \\
\text { per month with migraine, } \\
\text { absence from work, and the } \\
\text { need for medication decreased } \\
\text { during the evaluation period } \\
(p<0.05) \text {, while acupuncture } \\
\text { had the least amount of side- } \\
\text { effects }(p=0.021)\end{array}$ & $\begin{array}{l}\text { The study concluded that while } \\
\text { botulinum toxin-A injection, } \\
\text { acupuncture, and } \\
\text { pharmacological methods are all } \\
\text { effective in treating chronic } \\
\text { migraines, acupuncture is more } \\
\text { effective and associated with } \\
\text { fewer side effects than the other } \\
\text { methods }\end{array}$ \\
\hline
\end{tabular}


Table 1 continued

\begin{tabular}{|c|c|c|c|}
\hline $\begin{array}{l}\text { First } \\
\text { author of } \\
\text { study } \\
\text { (year) }\end{array}$ & Groups studied and intervention & Results and findings & Conclusions \\
\hline $\begin{array}{l}\text { Zhao et al. } \\
\qquad \begin{array}{l}(2017) \\
{[52]}\end{array}\end{array}$ & $\begin{array}{l}\text { Patients with the diagnosis of } \\
\text { migraine without aura } \\
(n=249) \\
\text { Patients received acupuncture, } \\
\text { sham acupuncture, or were } \\
\text { placed on a waiting-list. Patients } \\
\text { were followed for } 24 \text { weeks in } \\
\text { total }\end{array}$ & $\begin{array}{l}\text { At } 16 \text { weeks, the frequency of } \\
\text { migraine attacks decreased the } \\
\text { most with acupuncture (mean } \\
[S D] 3.2[2.1]) \text { compared with } \\
\text { sham acupuncture }(2.1[2.5]) \text { or } \\
\text { with no treatment }(1.4[2.5]) \text {. } \\
\text { The acupuncture group also had } \\
\text { the significantly lowest } \\
\text { frequency of migraine attacks, } \\
\text { migraine days, and VAS scores at } \\
\text { each follow-up time-point } \\
\text { between weeks } 4 \text { and } 24\end{array}$ & $\begin{array}{l}\text { True acupuncture might be more } \\
\text { efficacious in the long-term } \\
\text { treatment of migraines without } \\
\text { aura compared with sham } \\
\text { acupuncture or being on a } \\
\text { waiting list }\end{array}$ \\
\hline $\begin{array}{c}\text { Jiang et al. } \\
\text { (2018) } \\
{[54]}\end{array}$ & $\begin{array}{l}62 \text { RCTs involving } 4947 \text { total } \\
\text { patients diagnosed with } \\
\text { migraines }( \pm \text { aura) } \\
\text { Patients either received no } \\
\text { treatment, sham acupuncture, } \\
\text { medication, or treatment } \\
\text { acupuncture }\end{array}$ & $\begin{array}{l}\text { The acupuncture group had lower } \\
\text { VAS scores than the medication } \\
\text { group at } 1 \text { month post- } \\
\text { treatment (mean difference } 1.22 \text {, } \\
95 \% \text { CI }-1.57 \text { to }-0.87 \text { ) and } \\
\text { at } 1-3 \text { months post-treatment } \\
(-1.81,95 \% \text { CI }-3.42 \text { to } \\
-0.20) \text {. The acupuncture } \\
\text { group also had lower scores at } \\
1 \text { month post-treatment than } \\
\text { sham acupuncture }(-1.56,95 \% \\
\text { CI }-2.21 \text { to }-0.92) \text { Quality } \\
\text { of life scores were higher with } \\
\text { acupuncture than with sham } \\
\text { acupuncture }\end{array}$ & $\begin{array}{l}\text { Acupuncture is more effective at } \\
\text { treating and preventing } \\
\text { migraines than no treatment, } \\
\text { sham treatment, and } \\
\text { medication. Additionally, } \\
\text { acupuncture is associated with a } \\
\text { greater improvement of quality } \\
\text { of life post-treatment than sham } \\
\text { acupuncture }\end{array}$ \\
\hline
\end{tabular}


Table 1 continued

\begin{tabular}{|c|c|c|c|}
\hline $\begin{array}{l}\text { First } \\
\text { author of } \\
\text { study } \\
\text { (year) }\end{array}$ & Groups studied and intervention & Results and findings & Conclusions \\
\hline $\begin{array}{l}\text { Xu et al. } \\
\qquad(2018) \\
{[55]}\end{array}$ & $\begin{array}{l}14 \text { RCTs involving } 1155 \\
\text { participants diagnosed with } \\
\text { migraines without aura } \\
\text { Participants received acupuncture, } \\
\text { sham acupuncture, or medication }\end{array}$ & $\begin{array}{l}\text { Acupuncture reduced migraine } \\
\text { frequency (mean difference } \\
-1.50,95 \% \mathrm{CI}-2.32 \text { to } \\
-0.68 ; p<0.001) \text { and VAS } \\
\text { score }(0.97,95 \% \mathrm{CI}[0.63-1.31 ; \\
p<0.00001) \text { more than } \\
\text { medication, and had a higher } \\
\text { effective rate with less adverse } \\
\text { events. Acupuncture also } \\
\text { reduced migraine frequency } \\
(-1.05,95 \% \mathrm{CI}-1.75 \text { to } \\
-0.34] ; p=0.004) \text { and VAS } \\
\text { score }(-1.19 ; 95 \% \mathrm{CI}-1.75 \\
\text { to }-0.63 ; p<0.0001) \text { more } \\
\text { than sham acupuncture }\end{array}$ & $\begin{array}{l}\text { While most of the results in his } \\
\text { analysis favored acupuncture, } \\
\text { the study concluded that because } \\
\text { the quality of evidence } \\
\text { supporting the findings from } \\
\text { this study were low to very low, } \\
\text { further studies are warranted to } \\
\text { qualify the findings; however, } \\
\text { the authors did conclude that } \\
\text { acupuncture might be safer than } \\
\text { medication in treating migraines } \\
\text { without aura }\end{array}$ \\
\hline $\begin{array}{l}\text { Linde et al. } \\
\text { (2016) } \\
{[57]}\end{array}$ & $\begin{array}{l}22 \text { Trials were included that } \\
\text { involved a total of } 49851 \\
\text { participants } \\
\text { Patients either received no } \\
\text { treatment, sham acupuncture, } \\
\text { medication, or true acupuncture }\end{array}$ & $\begin{array}{l}\text { Acupuncture reduced migraine } \\
\text { frequency by at least half in } 41 \% \\
\text { of participants compared to } 17 \% \\
\text { with no treatment. Acupuncture } \\
\text { at least halved migraine } \\
\text { frequency in } 50 \% \text { of participants } \\
\text { compared to } 41 \% \text { with sham } \\
\text { acupuncture. Acupuncture at } \\
\text { least halved migraine frequency } \\
\text { in } 57 \% \text { of participants compared } \\
\text { to } 46 \% \text { who received medication }\end{array}$ & $\begin{array}{l}\text { Adding acupuncture as an } \\
\text { adjuvant therapy to traditional } \\
\text { treatments for migraines can } \\
\text { reduce frequency of migraines }\end{array}$ \\
\hline
\end{tabular}


Table 1 continued

\begin{tabular}{|c|c|c|c|}
\hline $\begin{array}{l}\text { First } \\
\text { author of } \\
\text { study } \\
\text { (year) }\end{array}$ & Groups studied and intervention & Results and findings & Conclusions \\
\hline $\begin{array}{c}\text { Wang et al. } \\
(2014) \\
{[47]}\end{array}$ & $\begin{array}{l}\text { Patients that suffer from frequent } \\
\text { migraine }(n=50) \\
\text { Patients were either assigned to a } \\
\text { real acupuncture group or a sham } \\
\text { acupuncture group }\end{array}$ & $\begin{array}{l}\text { Real acupuncture compared to } \\
\text { sham acupuncture was } \\
\text { associated with significantly } \\
\text { fewer migraine days (mean } \pm \\
\text { SD: } 5.2 \pm 5.0 \text { vs. } 10.1 \pm 7.1 \text {; } \\
p=0.008 \text { ), less severe migraine } \\
(2.18 \pm 1.05 \text { vs. } 2.93 \pm 0.61 ; \\
p=0.004 \text { ), more responders (19 } \\
\text { vs. } 7 ; p=0.002 \text { ), and increased } \\
\text { pain thresholds after } 20 \text { weeks of } \\
\text { treatment. These differences } \\
\text { between the groups were } \\
\text { maintained at the } 3 \text {-month } \\
\text { follow-up, but, not at the } \\
\text { 12-month follow-up }\end{array}$ & $\begin{array}{l}\text { Acupuncture is an effective and } \\
\text { safe option in the short-term } \\
\text { treatment of migraines; } \\
\text { however, larger RCTs will have } \\
\text { to be conducted to further } \\
\text { evaluate the efficacy and safety } \\
\text { of using acupuncture in the } \\
\text { long-term to treat migraine } \\
\text { headaches }\end{array}$ \\
\hline $\begin{array}{l}\text { Kuangshi } \\
\text { et al. } \\
(2015) \\
{[60]}\end{array}$ & $\begin{array}{l}\text { A total of } 12 \text { patients with } \\
\text { MWoA were recruited to } \\
\text { undergo resting-state fMRI } \\
\text { scanning, with rescanning after } \\
4 \text { weeks of standard acupuncture } \\
\text { treatment. Another } 12 \text { matched } \\
\text { healthy control subjects } \\
\text { underwent once scanning for } \\
\text { comparison }\end{array}$ & $\begin{array}{l}\text { Significantly decreased FC in the } \\
\text { rFPN and the decreased FC } \\
\text { could be reversed by } \\
\text { acupuncture treatment. The } \\
\text { changes of FC in MWoA } \\
\text { patients was negatively } \\
\text { correlated with the decrease of } \\
\text { VAS scores after treatment. This } \\
\text { study indicated that } \\
\text { acupuncture treatment for } \\
\text { MWoA patients was associated } \\
\text { with normalizing effects on the } \\
\text { intrinsic decreased FC of the } \\
\text { rFPN }\end{array}$ & $\begin{array}{l}\text { This study provided new insights } \\
\text { into the treatment-related neural } \\
\text { responses in MWoA patients } \\
\text { and suggested potential } \\
\text { functional pathways for the } \\
\text { evaluation of treatment in } \\
\text { MWoA patients. Future studies } \\
\text { are still in need to confirm the } \\
\text { current results and to elucidate } \\
\text { the complex neural mechanisms } \\
\text { of acupuncture treatment }\end{array}$ \\
\hline
\end{tabular}


Table 1 continued

\begin{tabular}{|c|c|c|c|}
\hline $\begin{array}{l}\text { First } \\
\text { author of } \\
\text { study } \\
\text { (year) }\end{array}$ & Groups studied and intervention & Results and findings & Conclusions \\
\hline $\begin{array}{l}\text { Yang et al. } \\
(2015) \\
(53)\end{array}$ & $\begin{array}{l}10 \text { RCTs with a total of } 997 \\
\text { participants with the diagnosis } \\
\text { of migraine } \\
\text { Participants were placed in the } \\
\text { verum manual acupuncture } \\
\text { group or the sham acupuncture } \\
\text { group }\end{array}$ & $\begin{array}{l}\text { Verum acupuncture was more } \\
\text { effective than sham acupuncture } \\
\text { on the basis of having a greater } \\
\text { reduction in the "not effective" } \\
\text { rate (relative risk } 0.24,95 \% \mathrm{CI} \\
0.15-0.38 ; p<0.0001 \text { ), and } \\
\text { reduced recurrence rate ( } 0.47 \text {, } \\
95 \% \mathrm{CI} 0.28-0.81 ; p=0.006) \text {. } \\
\text { No significant differences were } \\
\text { found between the groups in } \\
\text { terms of headache intensity, } \\
\text { frequency or duration, } \\
\text { accompanying symptoms, or use } \\
\text { of medication }\end{array}$ & $\begin{array}{l}\text { While these findings suggest that } \\
\text { verum acupuncture is superior } \\
\text { to sham acupuncture in treating } \\
\text { migraines, further large-scale } \\
\text { RCTs are warranted to verify } \\
\text { these findings }\end{array}$ \\
\hline
\end{tabular}

CI Confidence interval, EA electroacupuncture, EAP ear acupuncture, $F C$ functional connectivity, $f M R I$ functional magnetic resonance imaging, $M W o A$ migraine without aura, $R C T$ randomized clinical trial, $r F P N$ right frontoparietal network, $S D$ standard deviation, $V A S$ visual analog scale

Three studies have expanded the role that acupuncture could have in treating and managing patients with migraines.

The first is a 2018 study that used proton magnetic resonance spectroscopy imaging to investigate the neurochemical response to acupuncture treatment. In migraines, certain brain metabolites, such as $\mathrm{N}$-acetylaspartate (NAA), a marker of neural functionality, creatine (Cr), a marker of energy metabolism, and chlorine-containing compounds, a marker of membrane turnover, play an important role in the transmission of migraine pain. Most significantly, a decrease in NAA has been observed during a migraine attack. In this study, the authors found that after acupuncture therapy, there was a significantly increase in the mean $( \pm$ standard deviation [SD]) level of NAA/Cr from pre-treatment in both the left $(1.90 \pm 0.22 \mathrm{vs}$. $2.1 \pm 0.35 ; \quad p=0.006)$ and the right $(1.83 \pm 0.18 \quad$ vs. $\quad 1.96 \pm 0.14 ; \quad p=0.006)$ thalamus. This increase in NAA/Cr was found to be correlated with a decrease in headache intensity score following acupuncture treatment. The findings of this study reflects the impact of acupuncture on brain metabolic activity, which might play a role in reducing migraine pain [44].

The second is a 2019 study that used ear acupuncture (EAP) in 20 female patients to study the efficacy of this treatment for $\mathrm{CM}$ prophylaxis. The average $( \pm S D)$ reduction in migraine days/month after 1 month of treatment was $6.31 \pm 4.64$ days. Side effects noted in the study included pruritus, soreness, and transient pain with needle insertion. The study expands the scope of EAP as a treatment, which has been studied in the past for acute migraines, and supports the need for more studies with larger sample sizes and control groups [45].

The third is a 2020 retrospective study of 21,209 patients with migraine newly diagnosed 
in 2000-2012. The authors of this study reported that the acupuncture cohort $(n=1948$ patients, after 1:1 propensity score matching to control for demographic variables) had lower medical expenditure within 1 year of treatment intervention $(p<0.001)$, lower depression risk (adjusted hazard ratio [aHR] 0.61, 95\% confidence interval [CI] 0.39-0.95), and lower anxiety risk (aHR 0.51, 95\% CI 0.43-0.59) when compared to the non-acupuncture cohort ( $n=1948$ patients). A Kaplan-Meier analysis with 13-year follow-up data also revealed a statistically significant (log-rank test, $p<0.001$ ) decrease in cumulative incidence of depression and anxiety in the acupuncture cohort. The authors concluded that acupuncture may financially and therapeutically support migraine patients with common comorbidities such as anxiety and depression [46].

Other RCTs have sought to qualify acupuncture as a treatment option for migraines. A 2015 RCT compared real acupuncture to sham acupuncture, with the aim to determine the efficacy of real acupuncture in preventing frequent migraines. The authors reported that compared to the sham acupuncture group, the real acupuncture group reported fewer migraine days (mean \pm SD: $5.2 \pm 5.0$ vs. $10.1 \pm 7.1 ; p=0.008)$ and less severe migraine $(2.18 \pm 1.05$ vs. $2.93 \pm 0.61$; $p=0.004)$, and had more responders to treatment (19 vs. $7 ; p=0.002)$ at the end of the 20 -week treatment period. These significant differences between the groups were also maintained at a 3-month follow-up. However, the group differences were not maintained at a 12-month follow-up. The authors therefore concluded that acupuncture is an effective and safe treatment option for the short-term relief of migraines; however, larger RCTs will have to be conducted to further evaluate the efficacy and safety of acupuncture in the long term [47].

A 2018 single-blinded RCT investigated the effect of acupuncture on controlling acute migraine attacks by recording patient's pain intensity before and after acupuncture treatment for $4 \mathrm{~h}$ post-treatment. The main endpoint in this trial was the patient's pain intensity before and after acupuncture treatment. The authors reported that even though there was a significant difference between the treatment group and the control group in pain intensity scores at each interval for up to $1 \mathrm{~h}$ after acupuncture (all $p<0.05$ ), there was no significant difference between the two thereafter. Based on these findings, the authors concluded that there was no significant difference between acupuncture or a placebo in controlling migraines; however, acupuncture can be used in combination with other medical treatments to effectively manage migraines [48].

A double-blinded, multicenter RCT with 150 patients investigated the efficacy of acupuncture as prophylaxis for episodic migraine without aura in comparison to sham acupuncture. The acupuncture treatment (20 sessions) reduced the average number of migraine days at weeks $13-16$ (by 3.5 vs. 2.4 days for the sham acupuncture group; $95 \%$ CI -2.4 to -0.3 ; $p=0.005$ ) and at weeks $17-20$ (by 3.9 vs. 2.2 days for the sham acupuncture group; $95 \%$ $\mathrm{CI}-1.5$ to $-0.5 ; p<0.001)$. No severe adverse effects or statistically significant differences in needle perception were reported. The study concluded that manual acupuncture is a viable option for patients who do not respond or comply with drug therapy [49].

Another open-label RCT investigated the short- and long-term effectiveness of acupuncture versus standard pharmacological treatment in patients with a diagnosis of migraines. The main endpoint of the study was the difference in number of migraine days from baseline to post-treatment of both groups. The authors reported that in the short term, i.e., after 12-weeks of intervention, the number of migraine days was reduced more in the treatment group than in the control group (5.5 vs. 2.0 days). Additionally, in the short term, the responder rate to treatment (defined as $\geq 50 \%$ reduction in average monthly migraine day frequency) was greater in the acupuncture group than in the pharmacological group (50 vs. $27 \% ; p<0.05)$. Likewise, in the long term, i.e., 6 months post-treatment, the reduction in migraine days and the responder rate were more favorable in the treatment group than in the pharmacological, control group. Therefore, the authors concluded that acupuncture can be effective in both the short- and long term in 
treating migraines, and can serve as an adjuvant modality to traditional treatments [50].

A 2017 RCT compared the efficacy of botulinum toxin-A, another treatment modality approved for the treatment of migraines, with acupuncture and sodium valproate (as a control) in treating chronic migraines. The authors found that the visual analog scale (VAS) score was significantly reduced from baseline to 3 -months post-treatment in all of the groups studied $(p=0.0001)$. Of the three groups, the acupuncture group reported the greatest reduction in pain severity at the end of the 3-month study $(p=0.0001)$. Additionally, the trial showed that the number of days per month with migraine, absence from work, and the need for medication significantly decreased from pre-treatment to post-treatment at all of the time intervals in all of the three groups. Furthermore, the acupuncture group experienced fewer side effects than the group that received botulinum toxin-A $(p=0.021)$. The authors therefore concluded that while botulinum toxin-A, acupuncture, and pharmacological methods demonstrate some efficacy in treating chronic migraines, acupuncture demonstrates more effectiveness and is associated with fewer adverse events [51].

Zhao et al. evaluated the long-term efficacy of acupuncture in treating migraines without aura over the course of a 24 -week period. In this study, participants were divided into three groups: a true acupuncture group, sham acupuncture group, and a control group. The aim of this study was to quantify change in the frequency of migraine attacks from pre-treatment to week 16, as well as change in other variables, such as migraine days and VAS scores, all of which were compared at 4-week intervals over the treatment period. The authors found that the acupuncture group had the greatest reduction in frequency of migraine attacks at the end of the 16 weeks (mean \pm SD: $3.2 \pm 2.1$ ) compared to the sham acupuncture group (2.1 $\pm 2.5)$ or the waiting-list, control group (1.4 \pm $2.5)$. Both the difference between the acupuncture and sham groups, and the difference between the acupuncture and control groups were found to be statistically significant. Additionally, the acupuncture group was found to be associated with a significantly lower frequency of migraine attacks, migraine days, and VAS scores compared to both the sham acupuncture and control groups at each time-point between 4 and 24 weeks. The authors, hence, concluded that true acupuncture might be efficacious in the long-term treatment of migraines without aura [52].

Several meta-analysis have also attempted to better characterize the effectiveness of using acupuncture in the treatment of migraines. A 2015 meta-analysis looked at ten RCTs with a total of 997 participants to investigate the effectiveness of verum manual acupuncture compared to sham acupuncture. The authors assessed the "not effective" rate to determine the efficacy of the treatments in both of the groups. The manual acupuncture group was found to have a greater reduction in the "not effective" rate compared to the sham acupuncture group (relative risk [RR] 0.24, 95\% CI $0.15-0.38 ; p<0.0001)$. Additionally, verum acupuncture was also associated with a lower migraine recurrence rate than sham acupuncture $(0.47,95 \%$ CI $0.28-0.81 ; p=0.006)$. No significant differences were found between the groups in headache intensity, frequency or duration, accompanying symptoms, or medication usage. The authors concluded that while these findings suggest that verum acupuncture is superior to sham acupuncture in treating migraines, further large-scale RCTs are warranted to verify these findings [53].

One meta-analysis evaluated the efficacy and safety of acupuncture as a migraine treatment, and the effect of acupuncture on the quality of life of patients with migraines. The study included 62 trials, involving a total of 4947 participants. The analysis found that VAS scores were lower in the acupuncture group compared to the medication group at 1 month post-treatment (mean difference [MD] $-1.22,95 \%$ CI -1.57 to -0.87$)$. Similar findings were also reported at 1-3 months post-treatment (MD -1.81 , 95\% CI -3.42 to -0.20 ). The comparison of acupuncture and sham acupuncture revealed that acupuncture was associated with lower VAS scores at 1 month post-treatment (MD - 1.56, 95\% CI -2.21 to - 0.92). The study also investigated the effect that 
acupuncture has on the quality of life of those suffering from migraines. Looking at the Migraine-Specific Quality of Life Questionnaire (MSQ) scores, the authors found that the MSQ scores of the acupuncture group were higher than those of the sham acupuncture group at 1 month and at 1-3 months post-treatment. Furthermore, the analysis showed that acupuncture had a lower risk than medication of causing adverse events (risk difference $-0.16,95 \%$ CI -0.25 to -0.06 ). The authors concluded that acupuncture is more effective than no treatment, sham treatment, or medication in treating and preventing migraines and that it is also associated with a greater enhancement in quality of life compared to medication [54].

In another meta-analysis, 14 RCTs were reviewed that included a total of 1155 participants to investigate the effectiveness and safety of using acupuncture to treat migraines without aura compared to medication or sham acupuncture. The analysis looked at the frequency of migraine, number of migraine days, VAS score, effective rate, and adverse events. From the data acquired, the analysis found that acupuncture was more effective than medication at reducing the frequency of migraines (MD - 1.50, 95\% CI -2.32 to -0.68 ; $p<0.001$ ) and VAS score (MD 0.97, 95\% CI $0.63-1.31 ; p<0.00001)$ and had a significantly higher effective rate and fewer adverse events compared to medication (RR 0.29, 95\% CI $0.17-0.51 ; p<0.0001)$. When acupuncture was compared to sham acupuncture, acupuncture was found to be more effective in reducing the frequency of migraines (MD - 1.05, 95\% CI -1.75 to $-0.34 ; p=0.004)$ and VAS score (MD $-1.19,95 \%$ CI -1.75 to $-0.63, p<0.0001)$. While most of the results included in this analysis favored acupuncture, the authors concluded that because the quality of evidence supporting the findings from the RCTs included in the meta-analysis were low to very low, further studies are warranted to qualify the findings; however, the authors did conclude that acupuncture might be safer than medication in treating migraines without aura [55].

A meta-analysis that analyzed 13 RCTs involving 1559 patients reported that electroacupuncture was superior $(p<0.05)$ to a control treatment for migraines when compared with the following parameters: headache frequency (vs. Western medicine, sham-electroacupuncture, blank control), self-rating depression score (vs. Western medicine, blank control), self-rating anxiety scale (vs. blank control), clinical efficiency (vs. Western medicine, sham-electroacupuncture), and VAS score. The authors concluded that electroacupuncture is an effective treatment for migraines and possibly for depression and anxiety [56].

Another meta-analysis looked at 22 trials that included 4985 participants to compare acupuncture with no acupuncture, sham acupuncture, or medication. The main endpoint of this meta-analysis was headache frequency in adults with episodic migraines. The analysis revealed that $41 \%$ of patients who received acupuncture had a reduction in migraine frequency by at least half compared with $17 \%$ in those who received no treatment. Additionally, the comparison of true acupuncture to sham acupuncture showed that $50 \%$ of patients who received true acupuncture had a reduction in migraine frequency by at least half compared to $41 \%$ who received sham acupuncture. Furthermore, comparison of the true acupuncture and medication groups showed that $57 \%$ of patients who received true acupuncture had a reduction in migraine frequency by at least half compared with $46 \%$ who received medication. The authors concluded that using acupuncture as an adjuvant to other treatment modalities can reduce the frequency of migraine headaches [57].

While the majority of papers reviewed here advocate the incorporation of acupuncture into migraine management, there are acknowledgements that heterogeneity in statistical analyses, study population (e.g., sample size), and treatment methodology (e.g., length of acupuncture treatment, acupuncture point variations) make definitive conclusions difficult [58]. There is still a need for more high-quality evidence comparing acupuncture to other treatment modalities: control, sham acupuncture, acupoint gut embedding, drug therapy (including prophylaxis), and electroacupuncture $[56,59]$. 
Finally, a 2015 study investigating the effects of acupuncture treatment on the right frontoparietal network in patients with migraine without aura showed significantly decreased functional connectivity in the right frontoparietal network and that decreased functional connectivity could be reversed by acupuncture treatment. These data suggest that patients who have migraine without aura can have neural responses to acupuncture treatment [60].

\section{CONCLUSION}

Acupuncture is a form of traditional Chinese medicine that is performed by placing needles or pressure in specific locations on a patient's skin to achieve a therapeutic effect. Although used for a variety of disorders, one of the most common applications of acupuncture is to treat chronic pain, especially headache and migraine pain. Acknowledging the fact that migraine is one of the most disabling neurologic diseases worldwide, clinicians and researchers have made significant efforts into elucidating the pathophysiology of this complex disorder and searching for potent treatment approaches with minimal side effects. Migraines are difficult to treat, and current treatment options have many unwanted side effects, such as exacerbating headache pain in those with CM. Therefore, while the primary treatment for migraines is drug therapy, acupuncture is gaining increasing attention as a viable addition to the treatment management of migraine patients due to its measurable effects on both the duration and frequency of migraine attacks. Many studies suggest that acupuncture is a safe, helpful and available alternative therapy that may be beneficial to certain migraine patients. Nevertheless, further large-scale RCTs are warranted to further consolidate these findings and provide further support for the clinical value of acupuncture. Despite previous studies that have analyzed the effects of acupuncture on migraine, there is still a need for further investigation to ensure that the incorporation of acupuncture into migraine treatment management will have a positive outcome on patients. With regard to future studies, a new developed Acupuncture
Expectancy Scale may assist future research endeavors [61]. Future research studies could also benefit from regular follow-up treatments and interviews. Long-term follow-up of patients who have been treated with acupuncture for migraine could elucidate the long-term effects of this treatment.

\section{ACKNOWLEDGEMENTS}

Funding. No funding or sponsorship was received for this study or publication of this article.

Authorship. All named authors meet the International Committee of Medical Journal Editors (ICMJE) criteria for authorship for this article, take responsibility for the integrity of the work as a whole, and have given their approval for this version to be published.

Disclosures. Ivan Urits, Megha Patel, Mary Elizabeth Putz, Nikolas R Monteferrante, Diep Nguyen, Daniel An, Elyse M. Cornett, Jamal Hasoon, Alan D Kaye, and Omar Viswanath have nothing to disclose.

Compliance with Ethics Guidelines. This article is based on previously conducted studies and does not contain any studies with human participants or animals performed by any of the authors.

Data Availability. Data sharing is not applicable to this article as no datasets were generated or analyzed during the current study.

Open Access. This article is licensed under a Creative Commons Attribution-NonCommercial 4.0 International License, which permits any non-commercial use, sharing, adaptation, distribution and reproduction in any medium or format, as long as you give appropriate credit to the original author(s) and the source, provide a link to the Creative Commons licence, and indicate if changes were made. The images or other third party material in this article are included in the article's Creative Commons 
licence, unless indicated otherwise in a credit line to the material. If material is not included in the article's Creative Commons licence and your intended use is not permitted by statutory regulation or exceeds the permitted use, you will need to obtain permission directly from the copyright holder. To view a copy of this licence, visit http://creativecommons.org/licenses/bync/4.0/.

\section{REFERENCES}

1. Kelly RB, Willis J. Acupuncture for pain. Am Fam Physician. 2019;100(2):89-96.

2. May A, Schulte LH. Chronic migraine: risk factors, mechanisms and treatment. Nat Rev Neurol. 2016;12(8):455-64.

3. Peres MFP, Swerts DB, De Oliveira AB, Silva-Neto RP. Migraine patients' journey until a tertiary headache center: an observational study. J Headache Pain. 2019;20(1):88. https://doi.org/10. 1186/s10194-019-1039-3.

4. White A, Ernst E. A brief history of acupuncture. Rheumatology. 2004;43(5):662-3.

5. Vanderploeg $\mathrm{K}$, Yi X. Acupuncture in modern society. J Acupunct Meridian Stud. 2009;2(1):26-33.

6. [No authors listed]. NIH consensus conference. Acupuncture. JAMA. 1998;280(17):1518-24.

7. Nahin RL, Boineau R, Khalsa PS, Stussman BJ, Weber WJ. Evidence-Based Evaluation of Complementary Health Approaches for Pain Management in the United States. Mayo Clin Proc. 2016;91(9): 1292-306. https://doi.org/10.1016/j.mayocp.2016. 06.007.

8. Kaptchuk TJ. Acupuncture: theory, efficacy, and practice. Ann Intern Med. 2002;136(5):374-83.

9. Zijlstra FJ, van den Berg-de LI, Huygen FJPM, Klein J. Anti-inflammatory actions of acupuncture. Mediat Inflamm. 2003;12:807126.

10. Cho ZH, Chung SC, Jones JP, et al. New findings of the correlation between acupoints and corresponding brain cortices using functional MRI on JSTOR. Proc Natl Acad Sci USA. 1998;95(5):2670-3.

11. Cox J, Varatharajan S, Côté P. Effectiveness of acupuncture therapies to manage musculoskeletal disorders of the extremities: a systematic review. J Orthop Sports Phys Ther. 2016;46(6):409-29.

12. Dimitrova A, Murchison C, Oken B. Acupuncture for the treatment of peripheral neuropathy: a systematic review and meta-analysis. J Altern Complement Med. 2017;23(3):164-79.

13. Li M, Niu J, Yan P, Yao L, He W, Wang M, et al. The effectiveness and safety of acupuncture for depression: An overview of meta-analyses. Complement Ther Med. 2020;50:102202.

14. Qin X, Coyle ME, Yang L, et al. Acupuncture for recurrent urinary tract infection in women: a systematic review and meta-analysis. BJOG. 2020. https://doi.org/10.1111/1471-0528.16315.

15. Fan W, Kuang X, Hu J, et al. Acupuncture therapy for poststroke spastic hemiplegia: a systematic review and meta-analysis of randomized controlled trials. Complement Ther Clin Pract. 2020;40: 101176.

16. Natoli J, Manack A, Dean B, et al. Global prevalence of chronic migraine: a systematic review. Cephalalgia. 2010;30(5):599-609.

17. Buse DC, Manack AN, Fanning KM, et al. Chronic migraine prevalence, disability, and sociodemographic factors: results from the American migraine prevalence and prevention study. Headache. 2012;52(10):1456-70.

18. Burch R, Rizzoli P, Loder E. The prevalence and impact of migraine and severe headache in the United States: figures and trends from government health studies. Headache. 2018;58(4):496-505.

19. Lipton R, Stewart W, Diamond S, Diamond M, Reed $M$. Prevalence and burden of migraine in the United States: data from the American Migraine Study II. Headache. 2001;41(7):646-57.

20. Steiner TJ, Stovner LJ, Vos T, Jensen R, Katsarava Z. Migraine is first cause of disability in under 50s: will health politicians now take notice? J Headache Pain. 2018;19(1):17. https://doi.org/10.1186/ s10194-018-0846-2.

21. Feigin VL, Nichols E, Alam T, et al. Global, regional, and national burden of neurological disorders, 1990-2016: a systematic analysis for the Global Burden of Disease Study 2016. Lancet Neurol. 2019;18(5):459-80.

22. Peck J, Urits I, Zeien J, et al. A comprehensive review of over-the-counter treatment for chronic migraine headaches. Curr Pain Headache Rep. 2020;24(5):1-9. 
23. Qubty W, Patniyot I. Migraine pathophysiology. Pediatr Neurol. 2020;107:1-6.

24. Charles A. The pathophysiology of migraine: implications for clinical management. Lancet Neurol. 2018;17(2):174-82.

25. Dodick DW. Migraine. Lancet. 2018;391(10127): 1315-30.

26. Burch R. Migraine and tension-type headache: diagnosis and treatment. Med Clin N Am. 2019;103(2):215-33.

27. Katsarava Z, Buse DC, Manack AN, Lipton RB. Defining the differences between episodic migraine and chronic migraine. Curr Pain Headache Rep. 2012;16(1):86-92.

28. Classification Committee of The International Headache Society. The international classification of headache disorders 3rd edition. London: The International Headache Society. 2018.

29. Robblee J, Singh RH. Headache in the older population: causes, diagnoses, and treatments. Curr Pain Headache Rep. 2020;24(7):34.

30. Cologno D, Mazzeo A, Lecce B, et al. Triptans: over the migraine. Neurol Sci. 2012;33(Suppl 1):193-8.

31. Tfelt-Hansen P, Saxena PR, Dahlöf C, et al. Ergotamine in the acute treatment of migraine: a review and European consensus. Brain. 2000;123(Pt 1): 9-18.

32. Da Silva AN, Tepper SJ. Acute treatment of migraines. CNS Drugs. 2012;26(10):823-39.

33. Lipton RB, Dodick DW, Silberstein SD, et al. Singlepulse transcranial magnetic stimulation for acute treatment of migraine with aura: a randomised, double-blind, parallel-group, sham-controlled trial. Lancet Neurol. 2010;9(4):373-80.

34. Olla D, Sawyer J, Sommer N, Moore JB. Migraine treatment. Clin Plast Surg. 2020;47(2):295-303.

35. Diener HC, Dodick DW, Aurora SK, et al. OnabotulinumtoxinA for treatment of chronic migraine: results from the double-blind, randomized, placebo-controlled phase of the PREEMPT 2 trial. Cephalalgia. 2010;30(7):804-14.

36. Schoenen J, Vandersmissen B, Jeangette S, et al. Migraine prevention with a supraorbital transcutaneous stimulator: a randomized controlled trial. Neurology. 2013;80(8):697-704.

37. Puledda F, Shields K. Non-pharmacological approaches for migraine. Neurotherapeutics. 2018;15(2):336-45.
38. Coeytaux RR, Befus D. Role of acupuncture in the treatment or prevention of migraine, tension-type headache, or chronic headache disorders. Headache. 2016;56(7):1238-40.

39. Zhang X-T, Li X-Y, Zhao C, et al. An overview of systematic reviews of randomized controlled trials on acupuncture treating migraine. Pain Res Manag. 2019;2019:5930627.

40. Steiner TJ, Jensen R, Katsarava Z, et al. Aids to management of headache disorders in primary care (2nd edition). J Headache Pain. 2019; 20:57. https://doi.org/10.1186/s10194-018-0899-2.

41. Chen Y-Y, Li J, Chen M, Yue L, She T-W, Zheng H. Acupuncture versus propranolol in migraine prophylaxis: an indirect treatment comparison metaanalysis. J Neurol. 2020;267(1):14-25.

42. Doll E, Threlkeld B, Graff D, et al. Acupuncture in adult and pediatric headache: a narrative review. Neuropediatrics. 2019;50(6):346-52.

43. Patel PS, Minen MT. Complementary and integrative health treatments for migraine. J Neuroophthalmol. 2019;39(3):360-9.

44. Gu T, Lin L, Jiang Y, et al. Acupuncture therapy in treating migraine: results of a magnetic resonance spectroscopy imaging study. J Pain Res. 2018;11: 889-900.

45. Allais G, Sinigaglia S, Airola G, et al. Ear acupuncture in the prophylactic treatment of chronic migraine. Neurol Sci. 2019;40(1):211-2.

46. Liao C-C, Liao K-R, Lin C-L, Li J-M. Long-term effect of acupuncture on the medical expenditure and risk of depression and anxiety in migraine patients: a retrospective cohort study. Front Neurol. 2020;11: 321.

47. Wang Y, Xue CC, Helme R, Da Costa C, Zheng Z, Sherman KJ. Acupuncture for frequent migraine: a randomized, patient/assessor blinded, controlled trial with one-year follow-up. Evid Based Complement Altern Med. 2015;2015:920353.

48. Farahmand S, Shafazand S, Alinia E, Bagheri-Hariri $S$, Baratloo A. Pain management using acupuncture method in migraine headache patients; a single blinded randomized clinical trial. Anesthesiol Pain Med. 2018;8(6):e81688. https://doi.org/10.5812/ aapm. 81688 .

49. Xu S, Yu L, Luo X, et al. Manual acupuncture versus sham acupuncture and usual care for prophylaxis of episodic migraine without aura: multicentre, randomised clinical trial. BMJ. 2020;368:m697. https:// doi.org/10.1136/bmj.m697. 
50. Musil F, Pokladnikova J, Pavelek Z, Wang B, Guan $\mathrm{X}$, Vališ $\mathrm{M}$. Acupuncture in migraine prophylaxis in Czech patients: an open-label randomized controlled trial. Neuropsychiatr Dis Treat. 2018;14: 1221-8.

51. Naderinabi B, Saberi A, Hashemi $M$, et al. Acupuncture and botulinum toxin A injection in the treatment of chronic migraine: a randomized controlled study. Casp J Intern Med. 2017;8(3): 196-204.

52. Zhao L, Chen J, Li Y, et al. The long-term effect of acupuncture for migraine prophylaxis a randomized clinical trial. JAMA Intern Med. 2017;177(4): 508-15.

53. Yang Y, Que Q, Ye X, Hua ZG. Verum versus sham manual acupuncture for migraine: a systematic review of randomised controlled trials. Acupunct Med. 2016;34(2):76-83.

54. Jiang Y, Bai P, Chen H, Zhang XY, Tang XY, Chen $\mathrm{HQ}$, et al. The effect of acupuncture on the quality of life in patients with migraine: a systematic review and meta-analysis. Front Pharmacol. 2018;9: 1190. https://doi.org/10.3389/fphar.2018.01190.

55. Xu J, Zhang F-Q, Pei J, Ji J. Systematic review acupuncture for migraine without aura: a systematic review and meta-analysis. J Integr Med. 2018;16(5):312-21.
56. Li X, Dai Q, Shi Z, et al. Clinical efficacy and safety of electroacupuncture in migraine treatment: a systematic review and network meta-analysis. Am J Chin Med. 2019;47(8):1755-80.

57. Linde K, Allais G, Brinkhaus B, , et al. Acupuncture for the prevention of episodic migraine. Cochrane Database Syst Rev. 2016;(6):CD001218. https://doi. org/10.1002/14651858.CD001218.pub3.

58. Zhang N, Houle T, Hindiyeh N, Aurora SK. Systematic review: acupuncture vs standard pharmacological therapy for migraine prevention. Headache. 2020;60(2):309-17.

59. Li Y-X, Xiao X-L, Zhong D-L, et al. Effectiveness and safety of acupuncture for migraine: an overview of systematic reviews. Pain Res Manag. 2020;2020: 3825617. https://doi.org/10.1155/2020/3825617.

60. Li K, Zhang $\mathrm{Y}$, Ning $\mathrm{Y}$, et al. The effects of acupuncture treatment on the right frontoparietal network in migraine without aura patients. J Headache Pain. 2015;16:33. https://doi.org/10. 1186/s10194-015-0518-4.

61. Mao JJ, Armstrong K, Farrar JT, Bowman MA. Acupuncture Expectancy Scale: development and preliminary validation in China. Explore (NY) 2007;3(4):372-7. 